\title{
Modeling of Tomato Genotypes Stress-Tolerance by Comprehensive Assessment on Selective Media In Vitro ${ }^{\dagger}$
}

\author{
Tetiana Ivchenko*(D), Tetiana Miroshnichenko, Anna Mozgovska (D), Natalia Bashtan, Roman Krutko, \\ Sergiy Kondratenko, Oleksandr Kuts, Ivan Semenenko and Vasyl Kokoiko
}

check for

updates

Citation: Ivchenko, T;;

Miroshnichenko, T.; Mozgovska, A.;

Bashtan, N.; Krutko, R.; Kondratenko,

S.; Kuts, O.; Semenenko, I.; Kokoiko,

V. Modeling of Tomato Genotypes

Stress-Tolerance by Comprehensive

Assessment on Selective Media In

Vitro. Biol. Life Sci. Forum 2021, 4, 107.

https: / / doi.org/10.3390/

IECPS2020-08768

Academic Editor:

Yoselin Benitez-Alfonso

Published: 1 December 2020

Publisher's Note: MDPI stays neutral with regard to jurisdictional claims in published maps and institutional affiliations.

Copyright: (c) 2020 by the authors. Licensee MDPI, Basel, Switzerland. This article is an open access article distributed under the terms and conditions of the Creative Commons Attribution (CC BY) license (https:// creativecommons.org/licenses/by/ $4.0 /)$.
Institute of Vegetables and Melon Growing, National Academy of Agrarian Sciences of Ukraine, 62478 Kharkov, Ukraine; miroshnichenkotetiana@gmail.com (T.M.); mozgovskaja88@gmail.com (A.M.); bashtan021@gmail.com (N.B.); rvkrutko@gmail.com (R.K.); shtirlitsmail@gmail.com (S.K.); kutzalexandr@gmail.com (O.K.); semenen120912@ukr.net (I.S.); vasilvasilyovich@ukr.net (V.K.)

* Correspondence: tanivchenko@ukr.net; Tel.: +38-095-390-3251

+ Presented at the 1st International Electronic Conference on Plant Science, 1-15 December 2020; Available online: https://iecps2020.sciforum.net/.

Abstract: Global climate change has a negative impact on tomato production all around the world. This leads to annual losses of this crop due to disease and extreme weather conditions by $12-30 \%$. To increase the supply of vegetables and expand the range of genotypes adaptive to biotic and abiotic environmental factors, it is necessary to use laboratory methods and methods of mathematical modeling. These techniques are needed to assess and select promising sources of resistance in the breeding. The effectiveness of a complex rapid assessment of tissue culture in vitro in modified selective media MS (T. Murashige, F. Skoog, 1962) was studied in terms of viability and biometric parameters of calli and regenerated plants of 10 tomato genotypes. A two-factor experiment was performed. The factor A-18 variants of selective media, factor B-genotype. In each experimental variant, there were 20 numbers of explants in quadruplicate. The development of donor plants and the determination of the peroxidase level in their tissues wascarried out after 21 days of cultivation. At the same time, the level of productivity and stability of the samples in soil conditions was studied. The 71 studied parameters revealed 11 high degrees of correlation between the parameters of plants growing in selective media in vitro culture and the yield and resistance of tomatoes in soil conditions. These indicators were used to construct two variants of discriminant functions with the help of canonic discriminant analysis. This will make it possible to predict the level of stress resistance of tomato genotypes and simplify the assessment of a large number of genotypes by a set of traits in breeding practice.

Keywords: tomato; modeling; Solanum lycopersicum; screening; correlation; resistance

\section{Introduction}

Global climate changes have a negative impact on tomato production worldwide and in Ukraine, this has resulted in about $12-30 \%$ annual losses of tomato crop due to diseases and extreme weather conditions. In addition, over the past decade the output market of products, grown with alternative technologies, is one of the main directions of development of vegetable growing. The ratio of farms supplying natural agricultural products in the total land area and in the structure of agricultural enterprises in Ukraine is also growing. That is why it is important to create varieties and hybrids of tomatoes which can be used for different levels of production intensity, both conventional and alternative [1,2]. And although a significant part of economic characteristics is equally important for both traditional and alternative technologies, it is undoubtedly important to develop ways to create highly adaptable, resistant to abiotic and biotic factors sources suitable for alternative farming technologies. 
In modern plant breeding a range of different methodological approaches areused to create sources of resistance to phytopathogens and extreme weather conditions. Traditional selection methods are usually timeconsuming and the result of their application is the creation of genotypes with a significant number of heterogeneous genetic components in the created genotypes. The use of laboratory methods inin vitro culture [3], which allows the selection of cell populations resistant to selective factors and then regeneration of thewhole plant, gives a high efficiency for the assessment of tomato genotypes for resistance to disease and various extreme environmental factors. A plant or its tissue or organ that survives under the pressure of selective selection is a potential source of resilience/resistance. The result of somaclonal variability in in vitro culture is the formation of cell variants that differ from the original forms in such important breeding characteristics as productivity and fruit size; different levels of resistance to abiotic factors (e.g., resistance to salinity) [4-6] and biotic stresses, including diseases or pathogens $[2,7,8]$. The disadvantage of the method of cell selection is the low yield of resistant forms as well as the rapid loss of plant-acquired resistance during their cultivation in soil conditions.

Nowadays there is unrelated experimental data about the composition of selective media and methods for selecting stress-tolerant starting material for tomato breeding. This study is dedicated to determining the effectiveness of integrated use of genotype assessment methods in vitro culture on different selective media (salt, drought resistance, resistance to disease and deficiency/excess of nutrients and mathematical modeling methods for evaluation and differentiation of breeding material in creating new genotypes for intensive (Int) and organic (Org) tomato production systems.

\section{Materials and Methods}

We studied the effectiveness of a comprehensive rapid assessment in the culture of isolated cells in vitro on selective media MS [9] indicators of viability and biometric parameters of calluses and regenerating plants of 10 genotypes of tomato: the standard of biotic resistance-wild species Solanum chilense; the abiotic resistance standard-heatresistant line K-7311 created in IOB NAAS; hybrids $F_{1}$ Esmira and Zulfia (Rijk Zwaan) are recommended for intensive technologies; Golden konongin "Reine D’or", Potiron ecarlate, regional varieties of domestic selection-Seven, Dama and perspective breeding lines T-4, $\mathrm{T}-5$ are recommended for production by organic technologies.

The seeds of the test samples were inducted into a sterile culture by sequential sterilization in $96 \%$ ethanol (for $1 \mathrm{~min}$ ), then in a 30\% solution of sodium hypochlorite (for $30 \mathrm{~min}$ ). Then they were washed at least five times with sterile distilled water under sterile conditions (laminar box). The sterilized seeds for germination initiation were placed on a solid hormone-free nutrient medium according to the prescription of MS. That cultivation was performed under illumination of 2000 lux at a temperature of $23-25{ }^{\circ} \mathrm{C}$.

As test systems for assessing the response of genotypes to resistance to abiotic factors we used $10 \mathrm{~mm}$ long micro-cuttings which were planted on a selective medium MS with the addition of 5, 10,15 g/L NaCl (salinity stress); 0.05, 0.1, $0.15 \mathrm{~g} / \mathrm{L}$ of hydroxyproline $\left(\mathrm{C}_{5} \mathrm{H}_{9} \mathrm{NO}_{3}\right)$ (osmotic stress).

In order to model the resistance to the deficit/excess of mineral nutrients we used 6 variants of the nutrient medium MS, modified by the content of the main components $\left(\mathrm{A}-\mathrm{NH}_{4} \mathrm{NO}_{3} ; \mathrm{B}-\mathrm{KNO}_{3} ; \mathrm{C}-\mathrm{CaCl}_{2} \times 2 \mathrm{H}_{2} \mathrm{O}+\mathrm{KH}_{2} \mathrm{PO}_{4}+\mathrm{MgSO}_{4}\right):$ I. A-1.0; $\mathrm{B}-1.0$; C-1.0 (MS environment-control)); II. A-1.5; B-1.5; C-1.5; III. A-1.5; B-1.5; C-1.0; $I V . \mathrm{A}-1.0 ; \mathrm{B}-1.0 ; \mathrm{C}-0.5 ;$ V. A-0.5; B-0.5; C-1.0; VI. A-0.25; B-0.25; C-0.5.

We used morphogenic callus formed on cotyledon leaf segments obtained on MS medium with the addition of growth regulators $(2 \mathrm{mg} / \mathrm{L} \mathrm{IAA}$ and $2 \mathrm{mg} / \mathrm{L} \mathrm{BAP})$ as explants to assess the biotic stability of genotypes. The testing of the samples was performed on selective MS medium supplemented with 30 and $40 \%$ concentration of culture filtrate (FCL) of Alternaria spp. pathogens and Fusarium Link.).

After 28 days of cultivation on selective media there was performed the influence of selective factors on the biometric parameters of test tubes-the percentage of viability and 
rooting of explants, the height of regenerating plants and the length of their root system, callus volume and peroxidase levels in their tissues. The level of peroxidase in regenerating plants was determined by the method of A.N. Boyarkin [10]. To level the effect of in vitro culture on the phenotypic traits of regenerants, the data was normalized in relation to the control with obtaining indices, which allowed us to simultaneously analyze different indicators together. At the same time the level of productivity and stability of the studied samples was additionally determined in soil conditions. The experiments are two-factored, factor A-18 variants of selective media, factor B - genotype. The number of explants in one experimental variant-20 pieces. The experiment was repeated four times.

The collected data was statistically analyzed using Statistica 6.0. Correlations between different variables were calculated using the Goodman-Kruskal coefficient (G) [11]. Mathematical models were built using canonical discriminant analysis.

\section{Results}

\subsection{Rating of Abiotic Resistance of Tomato Genotypes}

The studies showed an inverse relationship between the number of viable explants and the content of both $\mathrm{NaCl}$ and hydroxyproline in the medium, but none of the experimental concentrations werelethal. The results of analysis of variance prove the significance of the impact on this indicator of both studied factors-the composition of the environment and the genotype.

The addition of $5 \mathrm{~g} / \mathrm{L} \mathrm{NaCl}$ to the nutrient medium did not significantly reduce the proportion of viable explants compared to the control variant in any of the samples (Figure 1a).

When the concentration of $\mathrm{NaCl}$ was increased to $10 \mathrm{~g} / \mathrm{L}$, the proportion of viable explants in the genotypes Dama, T-2, Potiron ecarlate and the wild species S. chilense significantly decreased. The highest concentration of $\mathrm{NaCl}$ studied $-15 \mathrm{~g} / \mathrm{L}-$ significantly reduced the viability of all studied samples. In the process of cultivation there was observed first whitening and death of the lower part of the micro-cuttings immersed in the medium, and then there was the death of the explant. Samples of Potiron ecarlate (the proportion of viable explants was 0.4 ) and Goldene koningin "Reine D'Or" (0.18) reacted the most strongly to the addition of $\mathrm{NaCl}$. The highest viability was characterized by the sample $\mathrm{T}-5$, in which the survival of explants at the maximum concentration of $\mathrm{NaCl}$ was at the control level and it was 0.93 , which is significantly higher than the reference genotypes of S. chilense (0.62) and K-7311 (0.6).

It was found that the concentration of hydroxyproline $0.05 \mathrm{~g} / \mathrm{L}$ also did not significantly affect the level of viability of microscales of most studied samples (Figure 1a). However, there was observed a significant decrease of viable explants in the proportion in the genotypes of Zulfia F1, T-5, Potiron ecarlate, T-2. The wild species of S. chilense reacted the most strongly to the content of hydroxyproline in the medium. The addition of $0.05 \mathrm{~g} / \mathrm{L}$ of hydroxyproline resulted in a decrease in the proportion of viable explants of this sample by $43 \%, 0.1 \mathrm{~g} / \mathrm{L}$-by $70 \%, 0.15 \mathrm{~g} / \mathrm{L}$-by $81 \%$. Seven and Goldene koningin "Reine D'Or" showed the highest viability on hydroxyproline media.

There was observed a significant difference between genotypes in terms of shoot height of regenerating plants (Figure 1b). According to the reaction to the addition of selective substances, all tested samples can be divided into several groups. Thus, the addition of $\mathrm{NaCl}$ and/or hydroxyproline to the nutrient medium resulted in a decrease in the average shoot height of regenerating plants compared to controls in samples of S. chilense, Potiron ecarlate and T-5. In samples K-7311 and Dama sobole height was also decreased but remained close to control. The relationship between the concentration of the selective agent and the height of the shoot is inversely proportional. In Goldene koningin "Reine D'Or" there was observed a similar phenomenon only on media with $\mathrm{NaCl}$, while on media with hydroxyproline regenerating plants in terms of sobole height exceeded the control by $12-13 \%$. Samples of Zulfia F1, Esmira F1, Seven and T-2 were also singled out, 
in which the sobole height on all studied selective media significantly exceeded the control indicators (by 12-68\%).

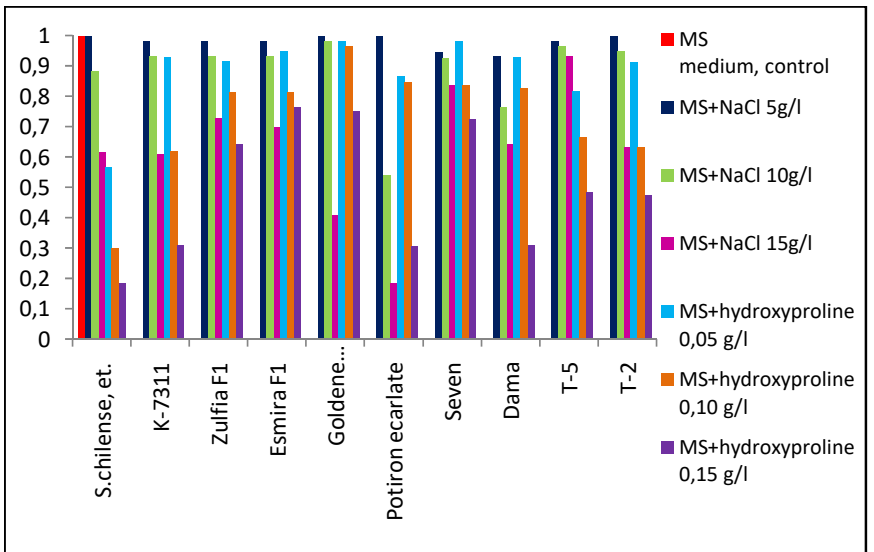

(a)

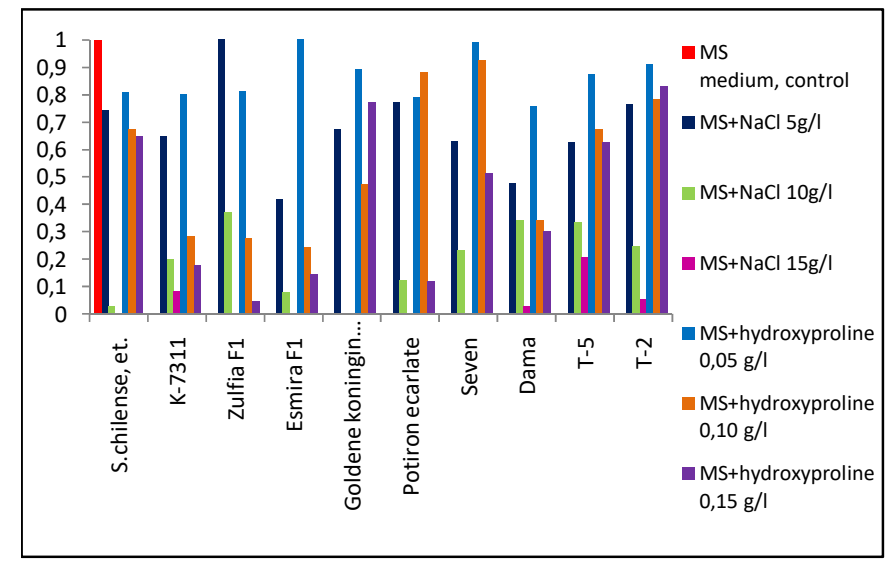

(c)

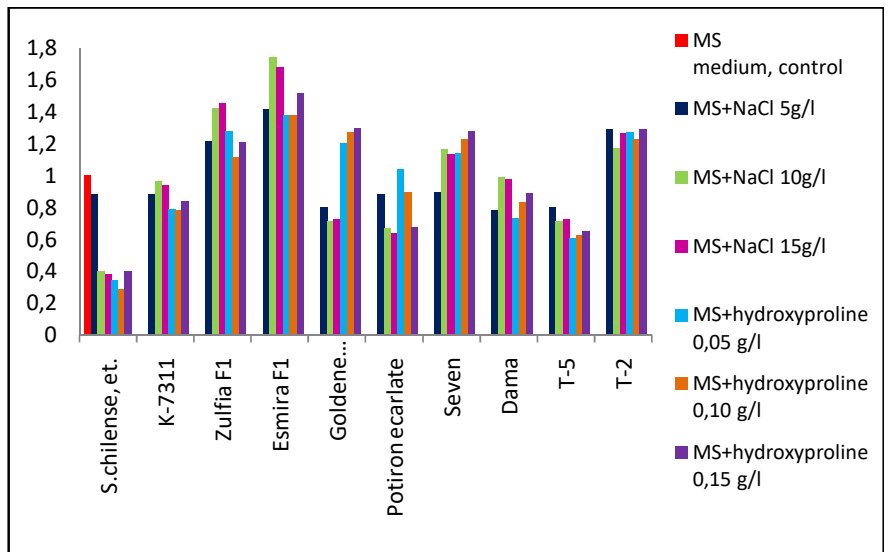

(b)

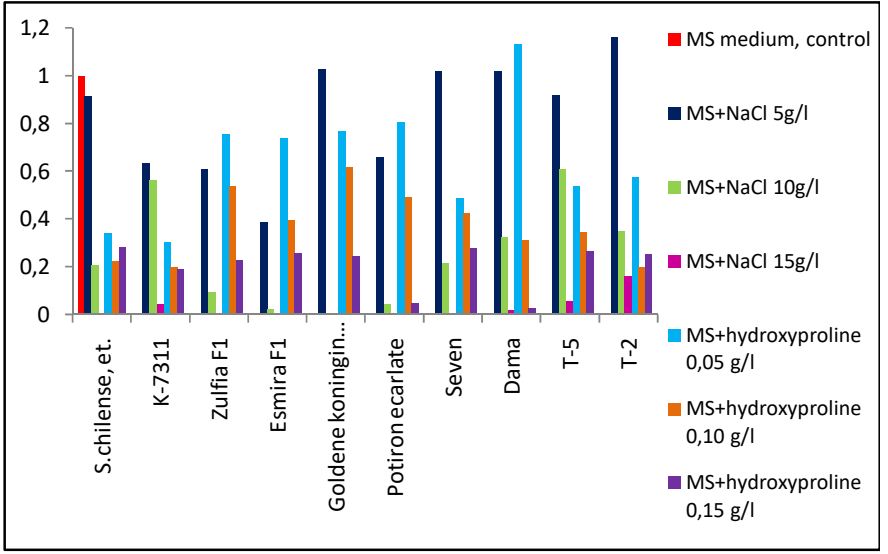

(d)

Figure 1. The effect of selective media with different concentrations of $\mathrm{NaCl}$ and hydroxyproline on characteristics of tomato regenerants, ratio to control: (a) proportion of living regenerants; (b) shoot height; (c) part of rooted regenerants; (d) root length.

The effect of different concentrations of $\mathrm{NaCl}$ and hydroxyproline in the nutrient medium was studied in relation to the development of the root system in thetest tubes. It was found that the addition of $\mathrm{NaCl}$ significantly reduced the percentage of rooted plants; there was found an inversely proportional relationship between the concentration of the selective agent and the frequency of rhizogenesis (Figure 1c). In the samples of Seven, Esmir F1 and Zulfia F1 in the variant with the maximum concentration of $\mathrm{NaCl}(15 \mathrm{~g} / \mathrm{L})$ the formation of the root system did not occur at all. The maximum proportion of rooting on this medium $(18.86 \%)$ was observed in sample T-5. In the variety Goldene koningin "Reine D'Or" rhizogenesis was completely stopped on a medium of $10 \mathrm{~g} / \mathrm{L} \mathrm{NaCl}$.

It was found that the concentration of hydroxyproline $50 \mathrm{mg} / \mathrm{L}$ does not significantly affect the percentage of rooting of plants of all studied samples. Increasing the concentration of the selective agent to $100 \mathrm{mg} / \mathrm{L}$ led to a decrease in the proportion of rooted plants. In the Seven and T-2 samples, the percentage of rooted regenerants decreased compared to the control by $5-16 \%$; in T-5 and S. chilense by $27-30 \%$; in other samples-more than $40 \%$. Therefore, the activity of rhizogenesis on this selective medium strongly depended on the genotypic characteristics of each sample. On medium with $150 \mathrm{mg} / \mathrm{L}$ of hydroxyproline, the root formation was markedly inhibited in samples K-7311, Zulfia F1, Esmira F1, Pot- 
iron ecarlate and Dama. S. chilense, T-2 and T-5 were the least sensitive to the effects of hydroxyproline on this indicator.

It was found that $\mathrm{NaCl}$ had a much stronger effect on the rhizogenesis of tomato regenerating plants than hydroxyproline. The length of the roots of regressive plants decreased proportionally with increasing concentration of both studied selective agents (Figure 1d). On media with minimal NaCl content in samples Seven, Dama, Zulfia F1, Goldene koningin "Reine D'Or", and in Dama-and on media with minimal hydroxyproline content, the root length was at the control level and even slightly exceeded it, which indicates a higher compared to other samples resistance of these genotypes to osmotic stress. However, a further increase in the concentration of selective substances led to a decrease in root length in these samples.

\subsection{Rating of Biotic Resistance of Tomato Genotypes}

For screening of tomato genotypes for disease resistance we studied the efficiency of cultivation of callus and tomato shoots on selective media with different concentrations of FCL of Alternia spp. and Fusarium spp. Cultivation of calluses on a nutrient medium with the addition of $30 \%$ concentration of FCL of the fungus Alternaria spp. did not allow to clearly differentiate the samples according to the indicator "callus volume" as its impact on the object was not significant (Figure 2a). Thus, in S. chilense (standard) it was-0.68. At the level of the standard there were samples of Esmira $F_{1}-0.66$; Zulfia $F_{1}-0.63$, Seven -0.63 , Goldene koningin -0.63 , Potiron ecarlate -0.63 . It was noted that the calluses were green, they had a loose texture with foci of organogenesis.

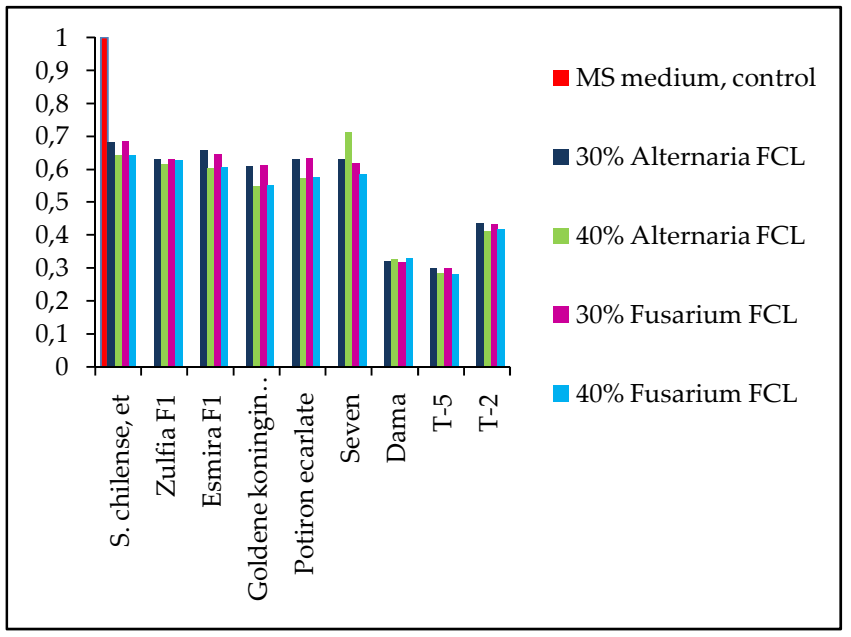

(a)

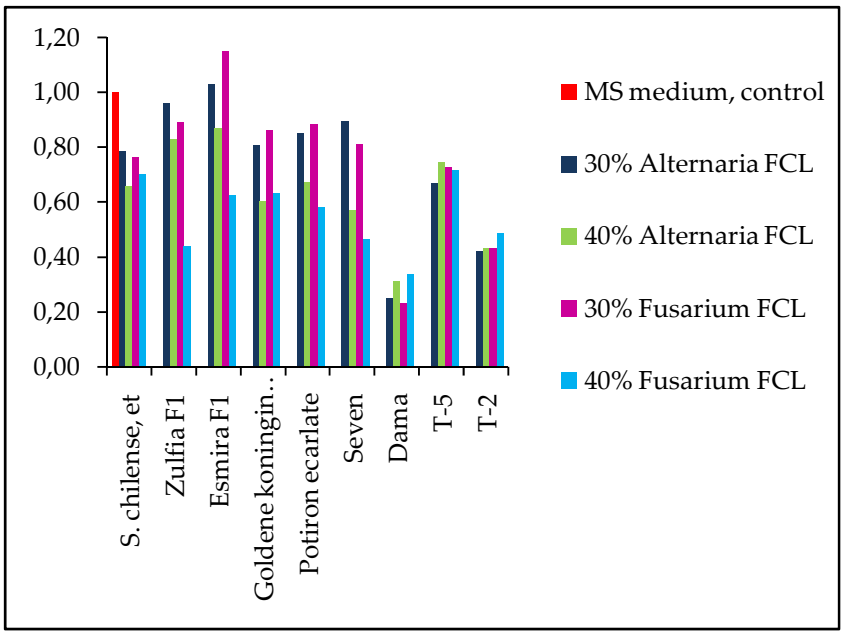

(b)

Figure 2. The effect of selective media with different concentrations of FCL of Alternaria and Fusarium spp. on characteristics of tomato explants, ratio to control: (a) callus volume; (b) height of regenerants.

The use of $40 \%$ concentration of FCL proved to be the most effective for differentiation of samples. Calluses in this variant of the selective medium had a dark green color, dense texture and without any organogenesis. This concentration reduced the morphological parameters of the samples by $50 \%$ towards the control variant. It should be noted that a higher concentration of FCL $(60 \%)$ in a selective medium, according to our previous studies, had quite a high toxic effect, which manifested itself in inhibiting the development of callus cells and regenerants and their destruction.

It is necessary to say that the $40 \%$ concentration of FCL Alternaria spp. in the nutrient medium caused a stronger inhibition of callus cell development in the standard S. chilense0.64 , Esmira $F_{1}-0.60$, Zulfia $F_{1}-0.62$, variety Seven -0.71 . Calluses had a dark green color, dense texture, without any organogenesis. 
In variants with a $30 \%$ concentration of FCL of the fungus Fusarium spp. the inhibition of callus development was also observed in all studied genotypes. The average values of the indicator "callus volume" in this variant compared with the standard varied in the range of 0.30-0.69 and was, respectively, in samples of S. chilense (standard)-0.69, Esmira $F_{1}-0.65$, Zulfia $F_{1}-0.63$, variety Seven-0.62. There was a slightly lower callus development in Goldene koningin and Potironecorlate-0.61 and 0.64 accordingly.

It was found that $40 \%$ concentration of FCL Fusarium spp. in the nutrient medium significantly affects the development of calluses, which allows to differentiate breeding samples by sensitivity to the selective medium. The index of the mean value of the "callus volume" was S. chilense - 0.64, the hybrid Esmira $\mathrm{F}_{1}-0.61$, Zulfiya $\mathrm{F}_{1}-0.63$, Seven-0.58. Compared to other samples of the $S$. chilense standard, hybrids of Esmir $F_{1}$ and Zulfia $F_{1}$, the Seven variety showed the least sensitivity to the action of selective factor.

According to the indicator "shoot height", the cultivation of regenerants by $30 \% \mathrm{FCL}$ fungus Alternaria spp. was in the standard S. chilense-0.79, Esmira $\mathrm{F}_{1}-1.03$, Seven0.89 and Zulfia $\mathrm{F}_{1}-0.96$. High shoot height was recorded in Goldene koningin and Potironecorlate varieties- -0.81 and 0.85 accordingly (Figure $2 b$ ).

On the place with the addition of $40 \%$ FCL Alternaria spp. there was observed a stronger inhibition of the development of callus-induced tomato shoots. Thus, in the studied samples, the indicator "shoot height" was as follows: in the standard S. chilense0.66, Esmira $F_{1}-0.87$, Zulfia $F_{1}-0.83$, variety Seven-0.57. Exteriorly the shoots on this variant of the selective medium differed in light green color, they had signs of significant tissue necrosis, and there wasn't observed root formation.

In variants with the addition to the nutrient medium of $30 \%$ FCL of the fungus Fusarium spp. the indicator of "height of shoot" was in S. chilense (standard) - 0.76, hybrid Esmira $\mathrm{F}_{1}-1.15$, Zulfia $\mathrm{F}_{1}-0.89$, variety Seven -0.81 , Goldene koningin -0.86 and Potiron ecarlate-0.89. A high level of resistance was observed in the cultivation of genotypes at $40 \%$ concentration of FCL of the fungus Fusarium spp. Thus, in the standard S. chilense0.70 , Esmira $\mathrm{F}_{1}-0.63$, varieties of Franch selection Goldene koningin and Potiron ecarlate0.63 and 0.58 accordingly. At the standard the height of shoots in the variety Seven-0.46 and hybrid Zulfia $\mathrm{F}_{1}-0.44$.

It was found that $40 \%$ concentration of FCL Fusarium spp. and Alternaria spp. in the nutrient medium MS significantly affected the indicators of "callus volume" and "shoot height", which allowed to differentiate the selection material of the tomato by sensitivity to the selective agent in culture in vitro.

\subsection{Rating of Resistance of Tomato Genotypes to Nutrient Deficiency}

In a series of experiments to assess the resistance of tomato genotypes to nutrient deficiency, we firstly confirmed the conclusion [12] about the need to adjust the composition of the nutrient medium in accordance with the biological needs of the culture and the characteristics of the genotype.

By all indications there was observed a minimal variation in biometric parameters in the standard sample S.chilense (Figure 3), which confirms its stability to different growing conditions as a wild species. S. chilense had a high development index even on the medium with the maximum nutrient deficiency in the experiment (variant $V I$ ), while most genotypes except for the samples Potiron ecarlate and Seven had lower indices of sobole height and number of leaves. The maximum variation in the development of the aboveground part was in the sample Esmira $\mathrm{F}_{1}$, a hybrid of intensive type, the yield of which depends on the mode of mineral nutrition. The index of sobole height of this sample varied from 0.97 on III medium to 3.00 on $V$ medium. The Zulfia $\mathrm{F}_{1}$ hybrid was stable under different feeding options, while the Potiron ecarlate variety, recommended for organic cultivation technologies, had higher root length index values at low levels of mineral nutrition on VI medium. Samples K-7311, Zulfia $\mathrm{F}_{1}$, Dama, T-2 had higher indices on the medium of $V$ sample with a high content of the mesos complex. 


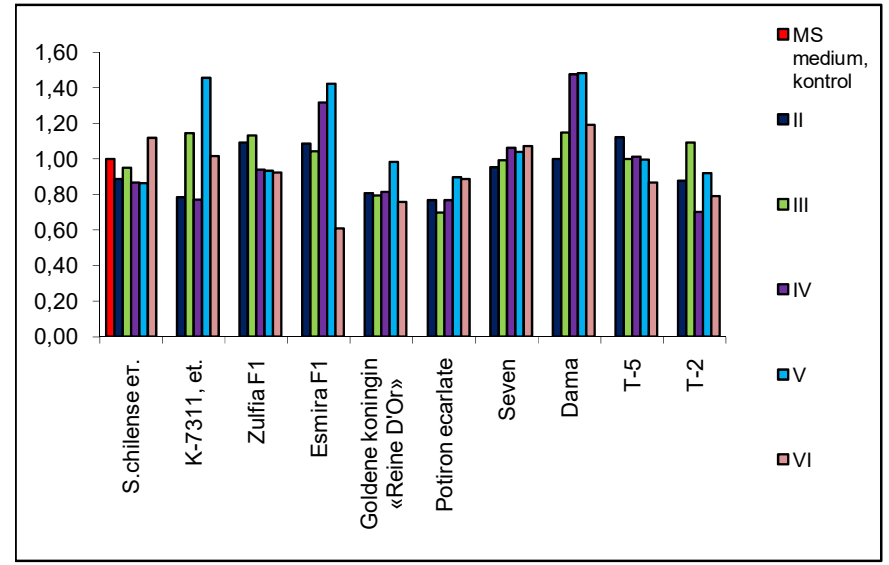

(a)

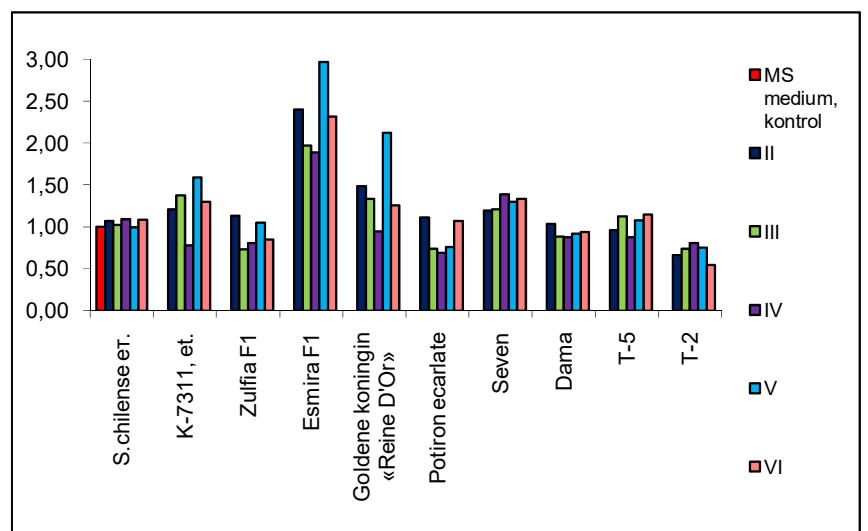

(c)

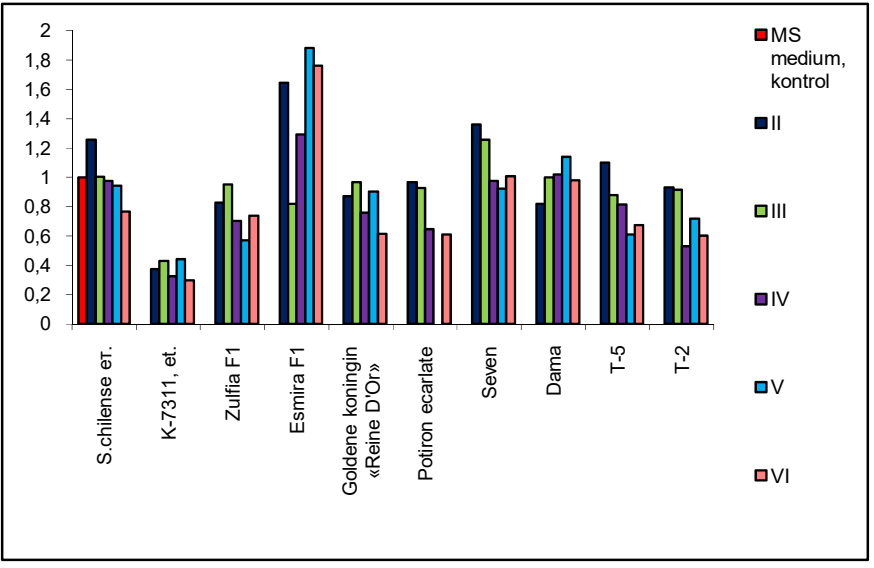

(b)

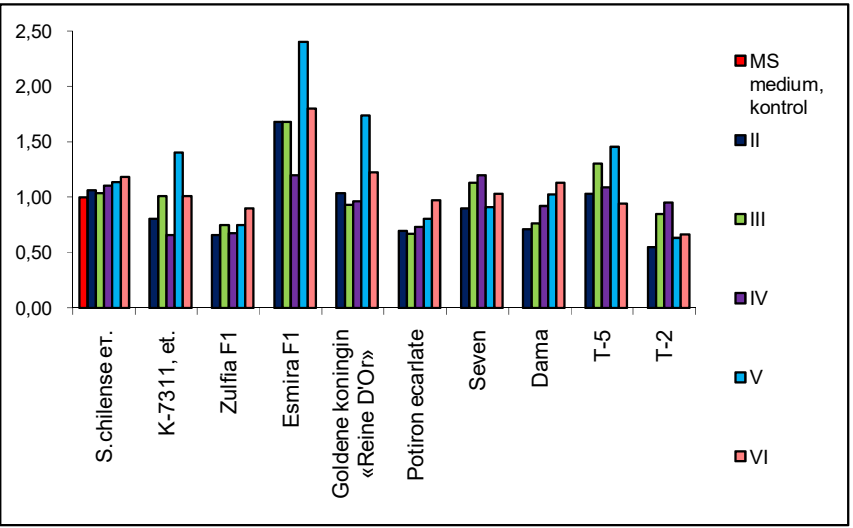

(d)

Figure 3. The effect of media with different ratio of mineral nutritional elements on characteristics of tomato regenerants, ratio to control: (a) shoot height; (b) number of leaves; (c) root length; (d) root development index.

\subsection{Determination of Peroxidase Levels in Test Plants Tubes}

Tubed tomato plants are the most sensitive to adverse factors because they are actively growing and developing. Therefore, to analyze the response of plant-regenerating tomatoes to cultivation under stress after 4 weeks cultivated on selective media, we established the activity of the redox enzyme peroxidase.

It was found that peroxidase activity in tomato regenerating plants increases in comparison with the control with increasing concentration of selective agents in the nutrient, which is a normal response of the plant to stress conditions. Hydroxyproline caused a stronger increase in peroxidase activity in most samples than $\mathrm{NaCl}$ did. The strongest response to the addition of selective substances to the nutrient medium was to the addition of selective substances to the nutrient medium such as Esmira $F_{1}$ (Table A1). Thus, in this sample on the medium with the maximum content of $\mathrm{NaCl}(15 \mathrm{~g} / \mathrm{L})$ the level of peroxidase activity exceeded the control variant by 8.63 times, on the medium with the maximum content of hydroxyproline $(0.15 \mathrm{~g} / \mathrm{L})$ - by 11.51 times. Furthermore, there was observed a strong response to selective media on this indicator in samples Zulfia F1, Goldene koningin "Reine D'Or", K-7311 and Seven, which indicates an active response of these samples to osmotic stress. There was observed quite a level of peroxidase activity on selective media in the standard sample $S$. chilense (the maximum excess of the control variant was recorded on a medium of $0.15 \mathrm{~g} / \mathrm{L}$ hydroxyproline and was 2.77 times), as well as in samples of Potiron ecarlate, T-5 and T-2. 
Peroxidase activity on selective media with the addition of $30 \%$ and $40 \%$ concentration of FCR Fusarium and Alternaria also had a pronounced tendency to rise with increasing concentration of a selective agent in nutrient media. The peroxidase activity in the sample of S. chilense when cultured by $30 \%$ and $40 \%$ FCR Fusarium and Alternaria was increased from 0.76 to 0.82 and from 1.37 to 1.26 accordingly, indicating high resistance to biotic stress of this wild kind. Zulfia $\mathrm{F}_{1}$ hybrid also had high peroxidase activity-from 1.98 to 6.10, which was estimated to show the highest resistance to diseases in soil conditions. In the sample K-7311 this figure ranged from 3.57 to 5.55. It should be noted that the samples Esmira $\mathrm{F}_{1}$, Goldene koningin, Potiron ecarlate did not respond to increasing the concentration of the selective agent in the environment by increasing the level of peroxidase. Thus, in Esmira $\mathrm{F}_{1}$, Goldene koningin and Potiron ecarlate this indicator even decreased accordingly from 2.63 to 1.46 , from 3.86 to 1.63 , from 2.05 to 1.05 , which indicates the high stability of these genotypes to biotic stress.

In studies to assess the resistance of tomato genotypes to deficiency-excess nutrients, peroxidase activity had the largest amplitude of variation on $I V$ and VI media (0.24-2.99 and 0.58-2.70 times from control accordingly), on $V$ and $I I$ variants its level was minimal (0.46-1.37 and 0.53-1.40 times the control, respectively), which indicates a low level of stress. Therefore, for the differentiation of tomato genotypes into groups according to the level of mineral nutrition, it is advisable to use nutrient media with a low content of KNO3 and NH4NO3 (VI variant) or with a high content of mineral salts (II variant).

\subsection{Development of a Model for Assessing the Stress Tolerance of Tomato Genotypes}

To develop models for assessing stress-tolerant samples suitable for cultivation at different levels of production intensity there were analyzed the indices of all 71 traits on selective media in vitro using cluster analysis functions which allowed us to establish eleven significant correlation coefficients (Table A2) and grouped genotypes with a similar response rate to cultivation on selective media. According to the reaction of genotypes the samples were divided into two groups (Figure 4).

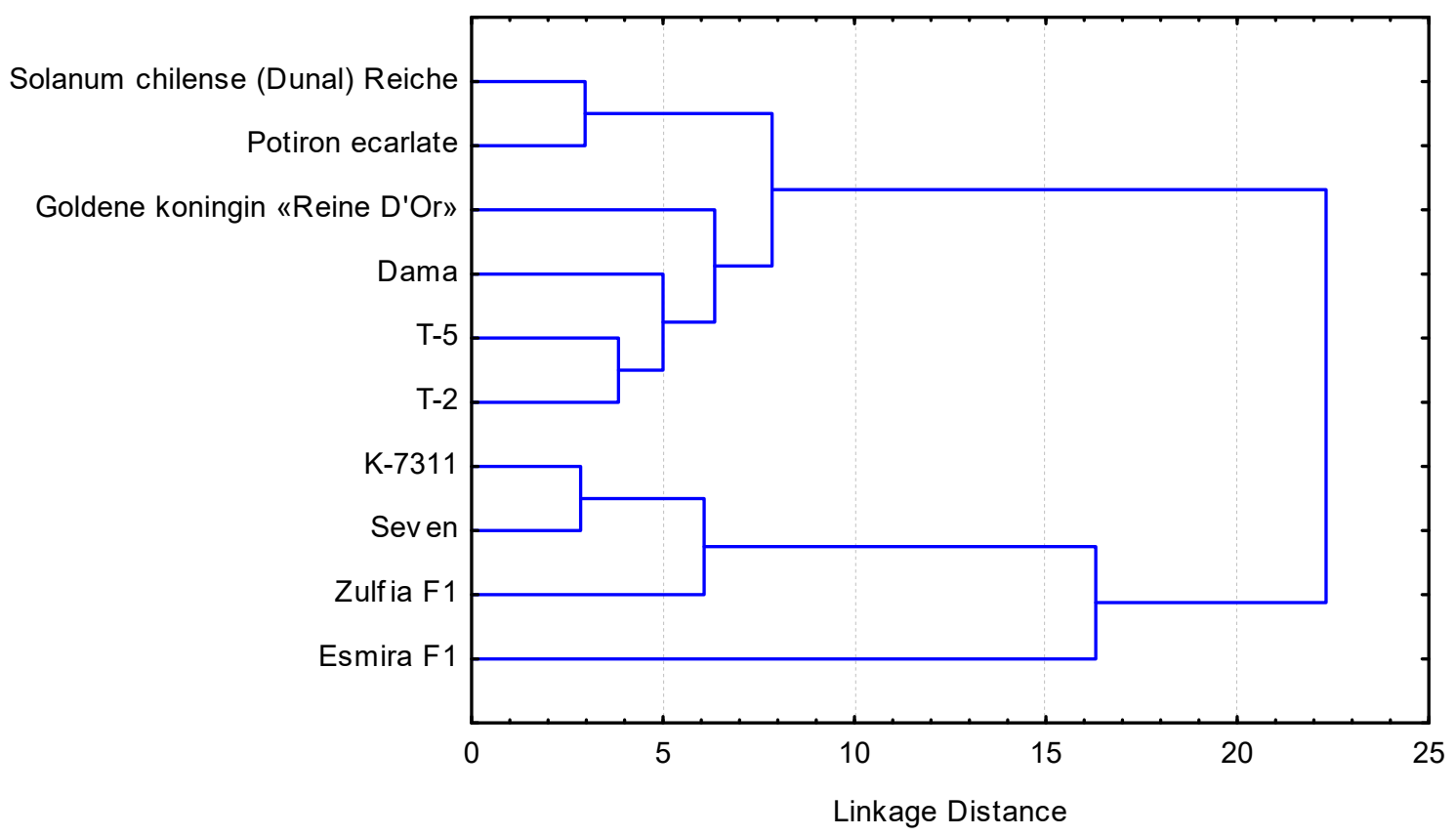

Figure 4. Tree diagram for 10 cases created by Ward's method, Euclidian distances between researches henotypes. 
The first group includes 6 samples (Solanum chilense, Potiron ecarlate, Golden konongin "Reine D'or", Dama, T-5, T-2), which according to the field assessment are suitable for growing by organic technologies, the second 4 samples (K-7311, Seven, Zulfia $F_{1}$, Esmira $\mathrm{F}_{1}$ ), high-yielding varieties and hybrids recommended for intensive tomato growing technologies.

Using the Goodman-Kruskal correlation coefficient [11], which allows us to analyze the relationships between nonparametric traits, all 71 traits of tomato genotypes in culture in vitro were additionally calculated, which allowed us to establish 11 significant correlation coefficients at $5 \%$ significance.

To build models of classification functions these 11 indicators were analyzed using canonical discriminant analysis, which allowed us to calculate a system of classification equations for dividing the samples into two separate groups.

$$
\begin{gathered}
\text { Group A }=-13.84-7.90 * \mathrm{PNa} 10-3.82 \mathrm{~d} 5.91 * \mathrm{PF} 40+30.24 * \mathrm{RLII} \\
\text { Group B }=-25.04+7.00 * \mathrm{PNa} 10+5.10 * \mathrm{PH} 0.05+1.51 * \mathrm{PF} 40-6.33 * \mathrm{RLII}
\end{gathered}
$$

$\mathrm{PNa} 10$ - Indicator of peroxidase activity on selective medium with the addition of Nacl $10 \mathrm{~g} / \mathrm{L}$;

PH0.05-Indicator of peroxidase activity on selective medium with the addition of hydroxyproline $0.05 \mathrm{~g} / \mathrm{L}$;

PF40-Indicator of peroxidase activity on selective medium with the addition of $40 \%$ FCL Fusarium;

RLII-The length of the root on the modified medium II.

The obtained system of discriminant equations allows the correct classification of samples into two groups (canonical correlation coefficient Canonical $\mathrm{R}=0.96$, Wilk's Lambda criterion $=0.075$ at the significance level p-level $=0.0038$ ).

\section{Discussion}

Evaluation of the interaction of genotype to abiotic and biotic environmental factors at different stages of the selection process is the most important element of greening selection and increasing efficiency for the evaluation of promising genotypes. Applied comprehensive evaluation in in vitro cultures of resistance to necrotrophic diseases, salt, drought resistance and resistance to different levels of mineral nutrition of ten different genetic constitutions of tomato genotypes has already provided a significant array of experimental data on the impact on biometrics indifferentiated and undifferentiated explants on selective media. Due to common non-specific mechanisms of resistance, it will be possible to accelerate the assessment of a large number of genotypes for resistance to biotic and abiotic factors and to determine the overall stress tolerance of tomato genotypes. It is known that one of the main mechanisms of systemic phytoresistance is the formation of reactive oxygen species, including hydrogen peroxide, in this regard, as bioindicators of the development of plant resistance identified changes in the activity of soluble and weakly bound to the cell wall forms peroxidase. Peroxidase is an inducible enzyme induced by physical, chemical, and biological factors, and its lability uses it as a marker to better characterize plant defense mechanisms. In addition, peroxidase is sensitive to various adverse effects and therefore the analysis of its content in regenerating plants has already allowed us to obtain objective information on the assessment of sensitivity/resistance of regenerating plants to stress.

By using the functions that have already been defined, it will be possible to accelerate the assessment of a large number of genotypes by a set of traits in breeding practice, primarily by resistance to biotic and abiotic factors. This methodological approach for the assessment of genotypes can be used in tomato culture in both the early and final stages of selection. 
It will also be possible to provide recommendations on the direction of use of new genotypes, their suitability for cultivation at different levels of intensity of tomato production, both intensive and organic systems of tomato production with high environmental safety.

The obtained system of discriminant equations has already been tested during the analysis of experimental samples. In our opinion, the sample T-5, which was created in IVM of NAAS, is in accordance with group A, and therefore can be recommended for cultivation by vegetable organic technology.

\section{Conclusions}

To develop models for assessing the stress tolerance of tomato samples to biotic and abiotic factors, the indices of 71 indicators on selective media in vitro culture were analyzed, which allowed the authors to group the samples by a similar rate of response to cultivation on selective media and to establish 11 significant correlations, which were used to build a system of discriminant equations.

By using the functions that have already been defined, it will be possible to accelerate the assessment of a large number of genotypes by a set of traits in breeding practice, primarily by resistance to biotic and abiotic factors. This methodological approach for the assessment of genotypes can be used in tomato culture in both the early and final stages of selection.

Supplementary Materials: The poster presentation is available online at https: / / www.mdpi.com/ article/10.3390/IECPS2020-08768/s1. 


\section{Appendix A}

Table A1. The level of peroxidase activity of tomato plants in vitro on selective media, indexes.

\begin{tabular}{|c|c|c|c|c|c|c|c|c|c|c|c|c|c|c|c|}
\hline Sample & $\mathrm{NaCl} 5 \mathrm{~g} / \mathrm{L}$ & $\mathrm{NaCl} 10 \mathrm{~g} / \mathrm{L}$ & $\mathrm{NaCl} 15 \mathrm{~g} / \mathrm{L}$ & $\begin{array}{c}\mathrm{C}_{5} \mathrm{H}_{9} \mathrm{NO}_{3} \\
0.05 \mathrm{~g} / \mathrm{L}\end{array}$ & $\begin{array}{c}\mathrm{C}_{5} \mathrm{H}_{9} \mathrm{NO}_{3} \\
0.10 \mathrm{~g} / \mathrm{L}\end{array}$ & $\begin{array}{c}\mathrm{C}_{5} \mathrm{H}_{9} \mathrm{NO}_{3} \\
0.15 \mathrm{~g} / \mathrm{L}\end{array}$ & $\begin{array}{c}30 \% \\
\text { Alternaria }\end{array}$ & $\begin{array}{c}40 \% \\
\text { Alternaria }\end{array}$ & $\begin{array}{c}30 \% \\
\text { Fusarium }\end{array}$ & $\begin{array}{c}40 \% \\
\text { Fusarium }\end{array}$ & II & III & IV & $\mathbf{V}$ & VI \\
\hline S. chilense, et. & 0.98 & 1.16 & 2.01 & 1.57 & 1.96 & 2.77 & 1.37 & 1.26 & 0.76 & 0.82 & 0.98 & 0.48 & 2.99 & 1.28 & 1.37 \\
\hline K-7311 & 2.30 & 3.66 & 4.55 & 3.00 & 4.10 & 5.98 & 3.57 & 4.87 & 4.16 & 5.55 & 0.61 & 0.73 & 1.13 & 0.74 & 0.83 \\
\hline Zulfia $F_{1}$ & 1.12 & 2.41 & 4.40 & 5.97 & 6.19 & 6.59 & 1.98 & 4.17 & 4.02 & 6.10 & 0.71 & 1.86 & 0.24 & 1.01 & 2.70 \\
\hline Esmira $\mathrm{F}_{1}$ & 1.32 & 4.66 & 8.63 & 6.83 & 12.59 & 11.51 & 2.63 & 2.37 & 1.66 & 1.46 & 1.33 & 0.79 & 1.68 & 1.12 & 1.78 \\
\hline $\begin{array}{l}\text { Goldene koningin } \\
\text { «Reine D'Or» }\end{array}$ & 1.33 & 2.62 & 3.12 & 2.65 & 3.95 & 6.12 & 3.00 & 1.63 & 3.86 & 2.17 & 0.68 & 0.86 & 0.97 & 0.57 & 0.79 \\
\hline Potiron ecarlate & 1.16 & 1.33 & 1.67 & 1.30 & 1.90 & 2.54 & 2.05 & 1.05 & 1.27 & 1.42 & 0.53 & 0.95 & 0.63 & 0.37 & 0.61 \\
\hline Seven & 0.73 & 4.39 & 5.18 & 4.47 & 3.51 & 6.08 & 4.41 & 5.83 & 4.52 & 5.17 & 0.74 & 0.43 & 1.28 & 1.09 & 1.04 \\
\hline Dama & 1.19 & 1.91 & 2.36 & 1.88 & 3.26 & 5.06 & 2.38 & 5.11 & 3.23 & 5.42 & 0.71 & 0.57 & 1.54 & 1.37 & 1.33 \\
\hline $\mathrm{T}-5$ & 1.17 & 1.45 & 1.68 & 1.28 & 1.74 & 2.52 & 0.78 & 4.18 & 1.57 & 4.40 & 0.86 & 0.69 & 0.53 & 0.61 & 0.73 \\
\hline $\mathrm{T}-2$ & 1.07 & 1.58 & 1.98 & 1.16 & 2.21 & 2.15 & 2.71 & 2.28 & 3.77 & 3.26 & 1.40 & 0.31 & 1.02 & 0.46 & 0.58 \\
\hline
\end{tabular}




\section{Appendix B}

Table A2. Calculation of Gamma correlation coefficients by the reaction of genotypes in culture in vitro on selective media.

\begin{tabular}{|c|c|c|}
\hline Indexes & Gamma & $p$-Level \\
\hline $\begin{array}{l}\text { 13. The average height of the sobole on a selective medium with the } \\
\text { addition of } \mathrm{Nacl} 5 \mathrm{~g} / \mathrm{L}\end{array}$ & 0.67 & 0.048 \\
\hline $\begin{array}{l}\text { 14. The average height of the shoot on a selective medium with the } \\
\text { addition of } \mathrm{Nacl} 10 \mathrm{~g} / \mathrm{L}\end{array}$ & 0.75 & 0.026 \\
\hline $\begin{array}{l}\text { 15. The average height of the shoot on a selective medium with the } \\
\text { addition of } \mathrm{Nacl} 15 \mathrm{~g} / \mathrm{L}\end{array}$ & 0.75 & 0.026 \\
\hline $\begin{array}{l}\text { 19. The average height of the shoot on a selective medium with the } \\
\text { addition of } 30 \% \text { FCL Alternaria }\end{array}$ & 0.83 & 0.014 \\
\hline $\begin{array}{l}\text { 32. Indicator of peroxidase activity on selective medium with the } \\
\text { addition of } \mathrm{Nacl} 10 \mathrm{~g} / \mathrm{L}\end{array}$ & 0.92 & 0.007 \\
\hline $\begin{array}{l}\text { 33. Indicator of peroxidase activity on selective medium with the } \\
\text { addition of Nacl } 15 \mathrm{~g} / \mathrm{L}\end{array}$ & 1.00 & 0.003 \\
\hline $\begin{array}{l}\text { 34. Indicator of peroxidase activity on selective medium with the } \\
\text { addition of hydroxyproline } 0.05 \mathrm{~g} / \mathrm{L}\end{array}$ & 1.00 & 0.003 \\
\hline $\begin{array}{l}\text { 35. Indicator of peroxidase activity on selective medium with the } \\
\text { addition of hydroxyproline } 0.10 \mathrm{~g} / \mathrm{L}\end{array}$ & 0.92 & 0.007 \\
\hline $\begin{array}{l}\text { 36. Indicator of peroxidase activity on selective medium with the } \\
\text { addition of hydroxyproline } 0.15 \mathrm{~g} / \mathrm{L}\end{array}$ & 0.83 & 0.014 \\
\hline $\begin{array}{l}\text { 39. Indicator of peroxidase activity on selective medium with the } \\
\text { addition of } 40 \% \text { FCL Fusarium }\end{array}$ & 0.75 & 0.027 \\
\hline 57. The length of the root on the modified medium II & 0.75 & 0.027 \\
\hline
\end{tabular}

\section{References}

1. Phillips, S.L.; Wolfe, M.S. Evolutionary plant breeding for low input systems. J. Agric. Sci. 2005, 143, 245-254. [CrossRef]

2. García-Gonzáles, R.; Quiroz, K.; Carrasco, B. Plant tissue culture: Current status, opportunities and challenges. Cienc. Investig. Agrar. 2010, 37, 5-30. [CrossRef]

3. Lebeda, A.; Švábová, L. Chapter 2: In vitro screening methods for assessing plant disease resistance. In Mass Screening Techniques for Selecting Crops Resistant to Diseases; Iinternational Atomic Energy Agency: Viena, Austria, 2010; pp. 5-46.

4. El-Sayed, A.; Mahdia, F.; Fouad, H. Responses to nacl salinity of tomato cultivated and breeding lines differing in salt tolerance in callus cultures. Int. J. Agric. Biol. 2004, 6, 19-26.

5. Emilio, A.; Cano, F.; Vicente, M. Evaluation of salt tolerance in cultivated and wild tomato species throug in vitroshoot apex culture. Plant Cell Tissue Organ Cult. 2005, 53, 19-26.

6. Hassan, N.M.; Serag, M.S.; El-Feky, F.M. In vitro selection of mung bean and tomato for improvingtolerance to NaCl. Ann. Appl. Biol. 2008, 152, 319-330. [CrossRef]

7. Švábová, A.; Lebeda, J. In vitroselection for improved plant resistance to toxin-producing pathogens. Phytopathology 2005, 153, 52-64. [CrossRef]

8. Srinivas, C.; Devi, D.; Murthy, K.; Mohan, C.; Lakshmeesha, T.; Singh, B.; Kalagatur, N.; Niranjana, S.; Hashem, A.; Alqarawi, A.; et al. Fusarium oxysporum $\mathrm{f}$. sp. lycopersici, causal agent of vascular wilt disease of tomato: Biology to diversity-A review. Saudi J. Biol. Sci. 2019, 26, 1315-1324. [CrossRef] [PubMed]

9. Murashige, T.A. Revised medium for rapid growth and bioassays with tobacco tissue culture. Physiol. Plant. 1962, 15, $473-497$. [CrossRef]

10. Ermakova, A.I.; Arasimovich, V.V.; Yaroch, N.P. Metodu Biochimichecrogo Issledovania Pasteniy, Agropromizdat, L.; The Lenizdat Publishing Group: Moscow, Russia, 1972; pp. 230-234.

11. Goodman, L.A.; Kruskal, W.H. Measures of association for cross classifications. J. Am. Stat. Assoc. 1954, 49, 732-764. [CrossRef]

12. Poothong, S.; Reed, B.M. Modeling the effects of mineral nutrition for improving growth and development of micropropagated red raspberries. Sci. Hortic. 2014, 165, 132-141. [CrossRef] 